\section{Out of the Woods}

The Norwegian commitment to scientific research

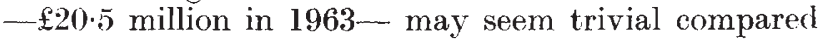
with the budgets of the United States or Britain, but the Norwegians are at least trying to use the funds as efficiently as possible. The Central Committee for Norwegian Research, the government's advisory body on the country's general research policy, completed a proposal for "Recommendations for a Norwegian Research Policy" in the autumn of 1966, and it has now been published for general discussion.

The report justifies its concern with long range planning by stating that "the decisions that are made. now will be of importance to developments for a long time to come, and it is important that the responsible bodies are able to make their decisions on the best possible basis.... The co-ordination of activities in various areas and the priority-rations of sectors can only be discussed thoroughly on the basis of an overall survey". At present, research policy questions are the concern not only of the government's board of research and the central committee but also of the individual ministries, the research councils, the scientific institutions and the industrial organizations. With only 2,700 research man-years by scientific personnel to account for in 1963, more than half of them at institutes connected with universities, the problem may not seem very great, but with limited resources it is even more important to plan and co-ordinate research allocations in the best way. The present organization has, according to the committee, "developed somewhat accidentally", and it is "dubious as to whether it leads to the most satisfactory allocation and the most effective use of the arailable resources". It also feels that priorities are reached arbitrarily in many areas, "greatly dependent on how clever the spokesmen for the various projects and research teams are".

The first point that the report makes is that the level of research in Norway, in terms of percentage of GNP, is at present far lower than in most countries0.59 per cent compared to 3.29 for the USA, 2.38 for Britain, 1.45 for France-and that more investment, especially in the universities and in applied research, must be undertaken.

The committee makes a number of recommendations, the chief of which is that the resources at the disposal of the research councils-which give research grants to universities, government departments, research institutes and industry - should be increased. The report points out that these councils are the most flexible source of funds; within their yearly budgets they can allocate money for immediate needs as well as support long-term projects. To simplify the organization, the report suggests that each government ministry be given responsibility for financing and formulating priorities in the area of applied research that falls within its administrative field of interest. It stresses that much more work needs to be done in the social sciences, in particular those areas of interest to government administration, such as psychology and sociology.

Naturally enough, a basic priority is the expansion of university training and, along with it, expansion of research. The report points out that money must be allocated for more non-scientific personnel, equipment and running costs as well, in order to make use of the research worker's full potential. Basic research in industry also needs to be expanded. possibly financed by increased government contracts. Even more important is a more comprehensive information service so that research results can reach the greatest number of interested people and industries.

\section{More Committees}

WITH the foundation of the Schools science and Technology Committee (SSTC), the Schools Council's Project Technology now has roval patronage and the Duke of Edinburgh's own action group. with suitable amendment, now has a more eoncrete base on which to build its activities. The two schemes, both designed to promote technology in schools, have been tackling the problem from rather different angles and it has become increasingly obvious to those involved that the fragmentation of effort was causing friction rather than enlightenment. The SSTC, chaired by the Duke of Edinburgh, will be responsible for Project Technology, and will promote and organize other activities on similar lines to help schools in their presentation of applied science.

Project Technology was begun in 1966, under the: direction of Mr Geoffrey Harrison (see Nature, 218, 716). and already more than 600 schools are in touch with latest developments through a regular bulletin and regional meetings. The action group came later to the scene when, at a meeting of the Association of Science Education last November. the Duke announced its formation. Under the chairmanship of Lord Jackson of Burnley the group discussed possibilities and recommended that the SSTC should be set up. With the Duke on the committee will be Vice-Admiral Sir Frank Mason, Dr C. G. Williams and $\mathrm{Mr}$ B. de Ferranti, all involved with engineering; Professor E. R. Laithwaite, Mr F. C. Brown and Mr C. English, representatives of further education: $\mathrm{Mr} \mathrm{J}$. J. Bryant, Mr E. Semper and Dr F. R. McKim, who have experience of teaching; $\mathrm{Mr}$ Harrison from Project Technology, and $\mathrm{Mr}$ J. A. G. Banks from the Schools Council. The intention is for these influential people to encourage industry to provide practical help and put pressure where required to make sure action is taken. Although a certain amount of money will be required, it is not thought that a large fund-raising scheme will be undertaken.

Another field in which the Schools Council is likely to meet a difference of opinion is that of sixth-form specialization and its effects on university entrance. A joint working party to investigate reforms of the curricula acceptable to both sides was announced in March by the Schools Council and the Standing Conference on University Entrance (see Nature, 21\%, 1199), but the membership of the group has only now: been announced. Professor Butler of Imperial College? has been elected chairman of the working party, the other members being Professors J. T. Allanson from Birmingham, R. H. Campbell from East Anglia and O. E. Lowenstein from Birmingham, Dr E. W. H. Briault from the Inner London Education Authority, $\mathrm{Mr} \mathrm{A}$. H. Jennings from Ecclesfield Grammar School, Mr J. S. Morrison of University College, Cambridge, Mr J. W. B. Ruffle from Bishop Wordsworth's School, Salisbury, Mr E. R. Taylor from Wolverhampton Grammar School and Miss D. Reader Harris from Sherborne School for Girls. 
Interested parties are invited to submit proposals or views to the working party, and are asked to send them to the secretary, Joint Working Party on Sixth Form Curriculum, the Schools Council, 160 Great Portland Street, London WI.

\section{Better Materials}

The Explosives Research and Development Establishment (ERDE) of the Ministry of Technology-at Waltham Abbey, Essex, last week held its first open days since it was established in 1945. One of the aims of the open days seems to have been to acquaint industry with the work in progress at ERDE on the development of polymers and the design of high strength composite materials. The 500 acre site at Waltham Abbey has a long association with explosives going back more than four conturies, first as a private gunpowder works and later as the Royal Gunpowder Factory. It has a network of canals which at one time used to be the means of transport within the site. The facilities at ERDE include remote handling equipment for the testing of now explosives and the

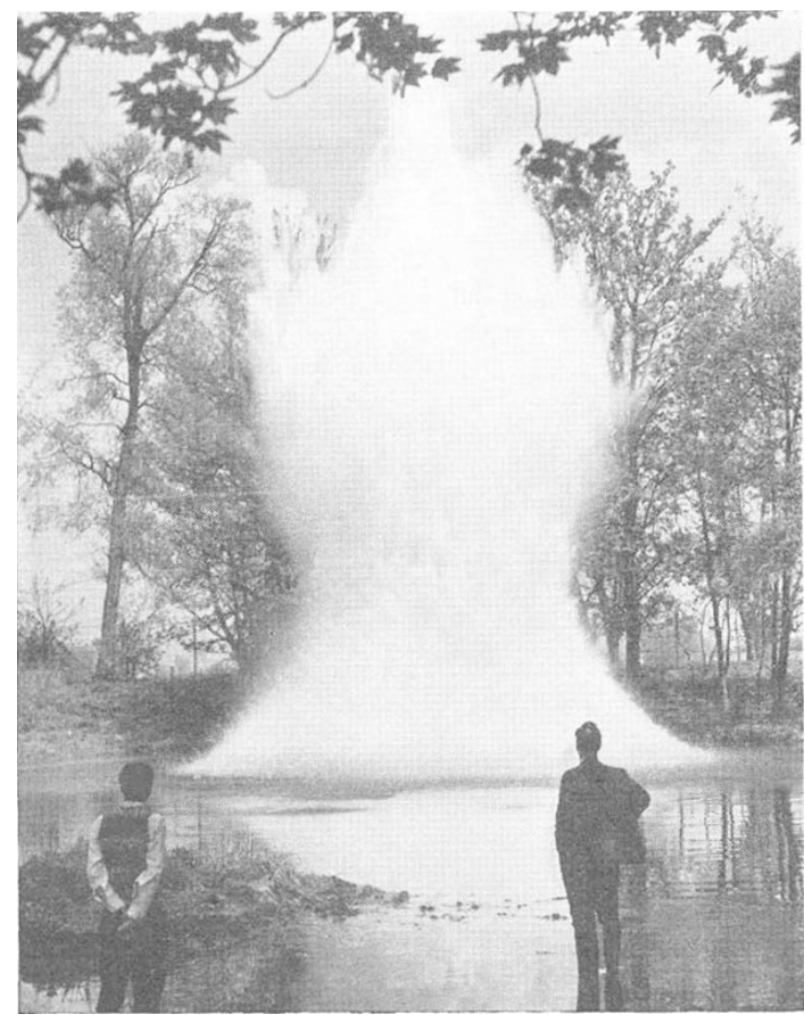

Testing underwater explosives at the Explosives Research and Development Establishment.

large-scale processing of rocket propellants. Although explosives and propellants still form the mainstay of the work at Waltham Abbey, about 30 per cent of the establishment's effort is now devoted to materials research. ERDE seems to have become particularly adept at developing materials of high strength by adding reinforcing fibres. Some of the new composite materials have properties which may make them suitable for applications in the aviation industry.

One of the lines of research under way is the investigation of thermoplastics containing various fibrous fillers as alternatives to glass-fibre. A number of fibres have been tried, including asbestos, carbon and whiskers of silicon carbide, in a range of thermoplastics. Asbestos and silicon carbide fibres have been particularly successful-silicon carbide giving the better properties but at a higher cost than asbestos.

Work on the strengthening of thermoplastics is leading on to the improvement of the properties of metals by the addition of reinforcing fibres. The addition of whiskers of silicon carbide to aluminium is producing the strength and high temperature properties of titanium at only half the weight. So far, reinforced aluminium has only been produced on a pilot plant basis, but it looks as if the chief difficulties -the manufacture of whiskers of silicon carbide and their alignment in the metal-have in principle at least been overcome. Now that the aviation industry is beginning to need the properties of titanium in the construction of supersonic aircraft, the prospects of aluminium reinforced by fibres look attractive. It is materials such as these which are likely to make weight problems such as those the American supersonic transport is facing at present a less important factor in the design of future generations of aircraft.

Apart from this work on composites, the materials sections at ERDE are also working on the improvement of polymers for applications such as flexible fuel tanks, dracones, arrester tapes for aircraft and hovercraft skirts. Here the problems are the degradation of the material by the effects of heat, light and fucls. By investigating the way in which the polymers break down under these influences, ways of modifying the polymers to make them more permanent are being developed.

\section{Analysis of MEDLARS}

A FULL-SCALE evaluation of the performance of MEDLARS (Medical Literature Analysis and Retrieval System) by the National Library of Medicine in the United States shows that the system is operating on average at about 58 per cent recall and 50 per cent precision, that is to say, it retrieves 58 per cent of relevant documents in response to a specific request, at the expense of having 50 per cent irrelevant documents retrieved at the same time. The results of the analysis, the first large-scale evaluation of a major operating information system, have recently been published in a report from the library (Evaluation of the MEDLARS Demand Search Service, US Dept of Health, Education and Welfare, 1968). Unfortunately the report is written in such a way that for a nonspecialist in information retrieval systems it is difficult to tell the wood from the trees. This is a pity, because the user of the service ought to be as aware of the results as the MEDLARS specialist, and indeed one of the rather cryptically written recommendations is that there is a great need for improvement in MEDILARS "at the interface between user and system".

The test programme was conducted impartially by a specially recruited "information systems evaluator", with the help of an advisory committee appointed by the director of the National Library of Medicine. An analysis was made of 300 actual requests made to the system in 1966 and 1967. It concentrated on the evaluation of the demand search function of MED. LARS, that is, the behaviour of retrospective literature 